\title{
Ocean redox conditions in a less- oxygenated Ordovician world: Perspectives from uranium isotope compositions of the Katian organic- rich mudrocks in southern Ontario, Canada
}

\author{
XINZE LU AND BRIAN KENDALL \\ University of Waterloo \\ Presenting Author: xlv@uwaterloo.ca
}

Understanding ocean redox conditions before the Late Ordovician mass extinction (LOME) event is important to test the hypothesis of expanded anoxia as a driver for extinction. Katian organic-rich mudrocks (ORM) of the Collingwood Member (CW) and overlying Rouge River Member (RR) were deposited in the Appalachian Basin and Michigan Basin (MB). Here, we present redox-sensitive trace metals (RSTM) and uranium isotope compositions $\left(\delta^{238} \mathrm{U}\right.$, relative to CRM145) to constrain local and global ocean redox conditions.

Both the CW and RR contain ORMs with pronounced enrichments of Mo relative to $U$, suggesting operation of an Fe$\mathrm{Mn}$ particulate shuttle. Most $\mathrm{CW}$ samples from basinal environment were primarily deposited from anoxic bottom waters $(\mathrm{Mo} / \mathrm{U}$ enrichment factor ratios greater than the modern seawater $\mathrm{Mo} / \mathrm{U}$ ratio $\left[\mathrm{Mo} / \mathrm{U}_{\mathrm{SW}}\right]$ ), with the most $\mathrm{U}$ - and Moenriched samples possibly representing euxinic conditions. By contrast, the $\mathrm{CW}$ near the Algonquin Arch (AA) was deposited from $\mathrm{O}_{2}$-bearing bottom waters $\left(0.1-1\right.$ of $\left.\mathrm{Mo} / \mathrm{U}_{\mathrm{SW}}\right)$. Predominantly oxic-suboxic with sporadic anoxic conditions are inferred for the RR.

Uranium isotope data was obtained for samples with appreciable authigenic $\mathrm{U}$ enrichments. The $\mathrm{CW}$ exhibits modest variation in $\delta^{238} \mathrm{U}_{\text {auth }}(-0.64 \%$ o to $-0.23 \%$; average $=-0.44 \%$ o) whereas the RR has a narrow range of $\delta^{238} \mathrm{U}_{\text {auth }}(-0.37 \%$ o to $-0.11 \%$; average $=-0.25 \%$ ). The $\mathrm{CW}$ from the anoxic $\mathrm{MB}$ localities has a higher average $\delta^{238} U_{\text {auth }}(-0.40 \%$ ) compared to suboxic settings near the AA $(-0.59 \%)$, whereas the RR exhibits little spatial variations in $\delta^{238} \mathrm{U}_{\text {auth }}$. Strong positive correlations between $\delta^{238} \mathrm{U}_{\text {auth }}$ and RSTM enrichments are observed for the $\mathrm{CW}$, indicating that redox gradients, rather than the particulate $\mathrm{Fe}-\mathrm{Mn}$ shuttle, controlled the magnitude of local $U$ isotope offsets between the water column and sediments. Therefore, the lowest $\delta^{238} U_{\text {auth }}(-0.64 \%$ ) is regarded as the highest possible $\delta^{238} \mathrm{U}$ of coeval seawater. A minimum of $2 \%$ global euxinic seafloor area is estimated from a $\mathrm{U}$ isotope mass balance model. No correlations between $\delta^{238} \mathrm{U}_{\text {auth }}$ and RSTM enrichments are observed for RR and hence coeval seawater $\delta^{238} U$ is difficult to deduce. Although the estimated global extent of ocean euxinia during $\mathrm{CW}$ deposition is similar to the second pulse of LOME, the Katian ocean anoxia/euxinia did not trigger a LOME-type of extinction. 